\title{
Measurement and Control of Coal Pipe Temperature of Coal Mills of PF Boiler
}

\author{
Karunamoy Chatterjee ${ }^{a,}$ Sankar Narayan Mahato $^{b}$, Subrata Chattopadhyay $^{c}$ \\ ${ }^{a}$ Electronics \& Communication Engineering, \\ Bankura Unnayani Institute of Engineering, Bankura, 722146, India \\ ${ }^{\mathrm{b}}$ Electrical Engineering, National Institute of Technology, Durgapur, 713209, India \\ ${ }^{c}$ Electrical Engineering, National Institute of Technical Teachers Training \& Research, Kolkata, India
}

\begin{abstract}
Power plant boiler had no arrangement of measure the coal pipe temperature in a continuous basis, though it is an important parameter for any coal fired large boiler. As pulverized coal flows through the long coal-pipe by the help of flow of hot air as a carrier, coal pipe temperature is only the measurement of the coal flow through the pipe to boiler. Low temperature indicates improper flow of pulverized coal through the pipe. So due to no continuous measurement of these parameters we can't know about the flow profile of coal through pulveriser outlet pipes. Sometimes the pipe got choked and we were not aware of that for a long time. That caused our equipment loss i.e. we had to stop the pulveriser for a long time for de-choking the large size coal pipe. And indirectly it caused loss of power generation and also affected the economical figure of our power house. So to overcome that kind of losses we have to measure the coal pipe temperature in regular basis.
\end{abstract}

\section{INTRODUCTION}

According to the boiler design pulverized coal flows through the long coal-pipe by the help of flow of hot air as a carrier. As there was no automation we couldn't know the flow profile of pulverized coal through coal pipe. Coal carried by hot air so if the coal pipe is sufficiently heated, that indicates the proper coal flow through pipe. But again we had no arrangement to measure coal pipe temperature also. As a result frequently coal pipe got choked due to improper coal flow and we were not aware of that for a long time. Once the huge pipe got choked we had to spent more manpower as well as more maintenance cost for de-choking purpose. Frequently our pulveriser used to be stopped and directly it caused loss of power generation and also affected the economical figure of our power house. In this paper our objective is to measure the temperature of the coal pipe to prevent the de choking of the coal flow pipe.

A Coal mill model using Evolutionary computation technique reported in [1]. Expertise in mill modelling has been developed over many years which are mainly empirical. Although some progress has been made in the development of mill models, it is still very difficult to obtain exact analytical results because of the intrinsic complexity of coal pulverising process which comprises of two-phase flow and heat-transfer process. Using conventional methods, many results are reported in the form of transfer functions which are not derived from physical principles [2]. However with the advance in modern computer control systems, all measured signals can be stored in data bases covering long periods of time. These data can be used for modelling without additional field tests, but require suitable modelling techniques which are to be identified properly. A novel coal mill modelling technique for E-type coal mill and dynamic behaviour are developed using genetic algorithms [3]. Genetic Algorithms (GAs) have been successfully applied to problems in business, engineering, and science. Gas are stochastic, population-based search and optimization algorithms inspired by the process of natural selection and genetics [4]. A major characteristic of GA is that, it works with a population, unlike other classical approaches which operate on a single solution at a time. A fitness function is needed for differentiating between good and bad solutions. Unlike classical optimization techniques, the fitness function of GAs may be presented in mathematical terms, or as a complex computer simulation, or even in terms of subjective human evaluation. Fitness function generates a differential signal in accordance with which GAs guide the evolution of solutions to the problem [5]. Selection chooses the individuals with higher fitness as parents of the next generation. In other words, selection operator is intended to improve average quality of the population by giving superior individuals a better chance to get copied into the next generation [6] [7]. GA is tried in some of the thermal power plant modelling and estimation problems [8] - [10]. Modelling of the Measurement of Flow Measurement of the Flow of Hot Air in Straight Tube of Blast Furnace [11] was developed. But no strict methodology is applied to protect the choking of coal flow pipe. This proposes hot air temperature measurement system through coal flow pipe can eliminate the problem of de choking of coal flow pipe. Fig.1. shows the effect of choking of coal flow pipe. And as a result of pipe choking coal burner also damaged as shown in Fig. 2. 


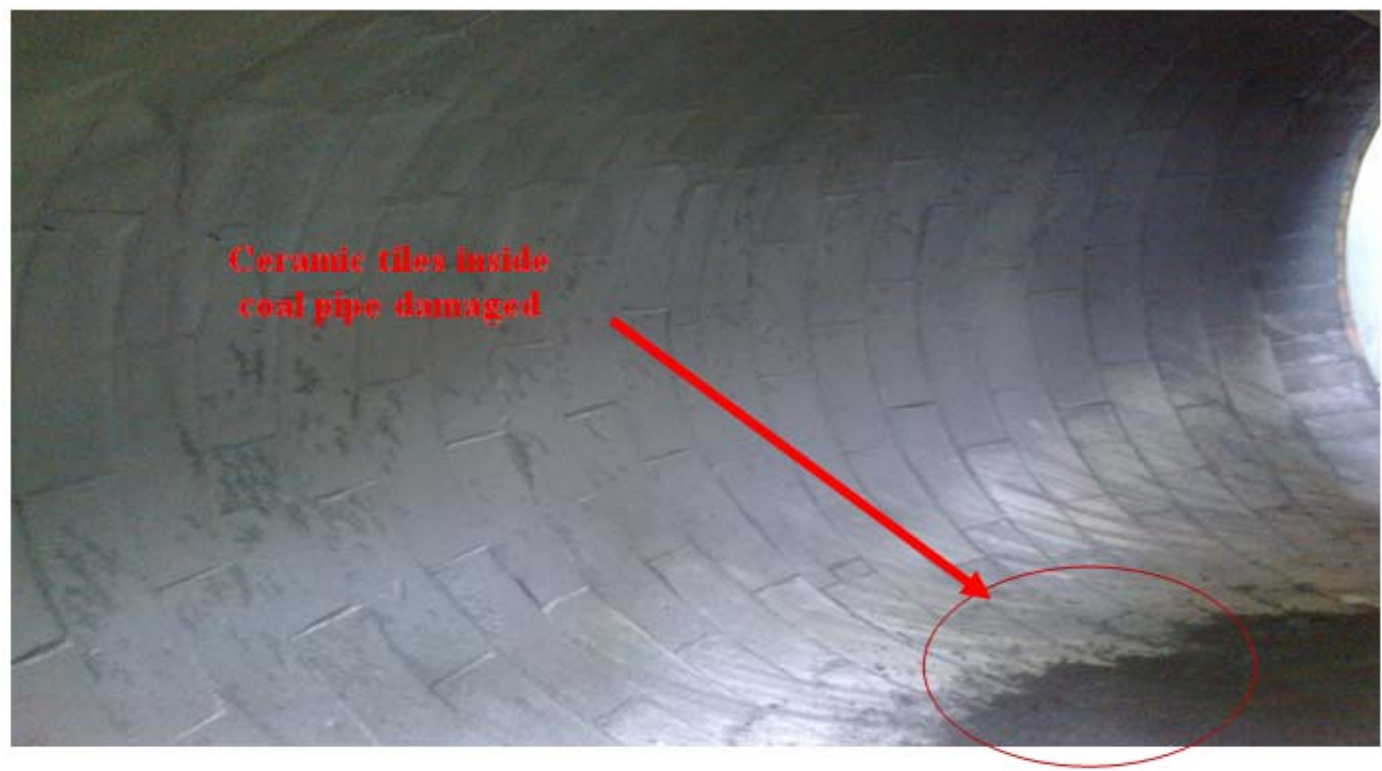

Fig. 1. Ceramic tiles damaged due to coal pipe de-choking work.

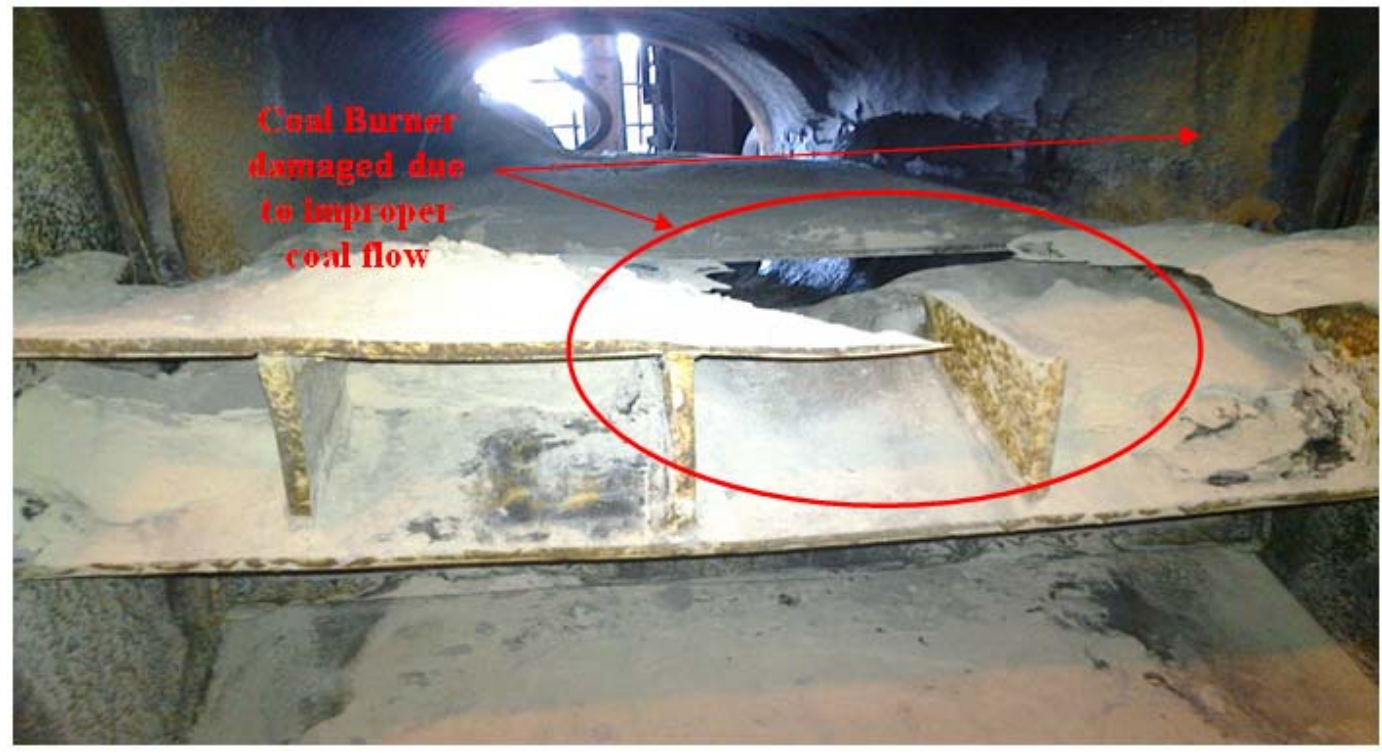

Fig. 2. Coal burner damaged due to improper coal flow.

\section{DESIGN METHOD}

So to overcome that kind of losses we have to measure the coal pipe temperature in regular basis. First we started measure by manually, but the problem can't be solved, as there were human errors in every measure. So to stop manual interfere, we developed automation for measurement of coal pipe temperature, adopting new technology by using concept of "Field bus signal processing". We used a multi-channel (32 channel) data logger as scanner, which can scan a numbers of RTD / Thermocouple signal. As we have eight numbers (08) of coal mill and each coal mill has four outlet coal pipes, so we have to measure 32 numbers of coal pipe temperature. We design and procure 32 numbers of special type surface mounted RTD. Fixed the RTD on each and every coal pipe before entering at the burner area. 32 numbers of RTD signals are connected to a central control junction box and then connected to the temperature scanner. Then established a communication between Data logger or Temperature Scanner to DCS system through a single pair cable. A programme or logic build on DCS software to provide uninterrupted measurement of process value i.e., coal pipe temperature. Also we configured a graphical representation of all of those 32 numbers of coal pipe temperature for plant operators and also configured alarms for low temperature i.e., temperature $<65{ }^{\circ} \mathrm{C}$, so that actual coal flow can be assumed and coal pipe choking can be minimized.

By the help of various method of analysis we find out a common solution to build an automation system for monitoring and measurement of coal pipe temperature to overcome our problem. The block diagram is shown Fig. 3. 


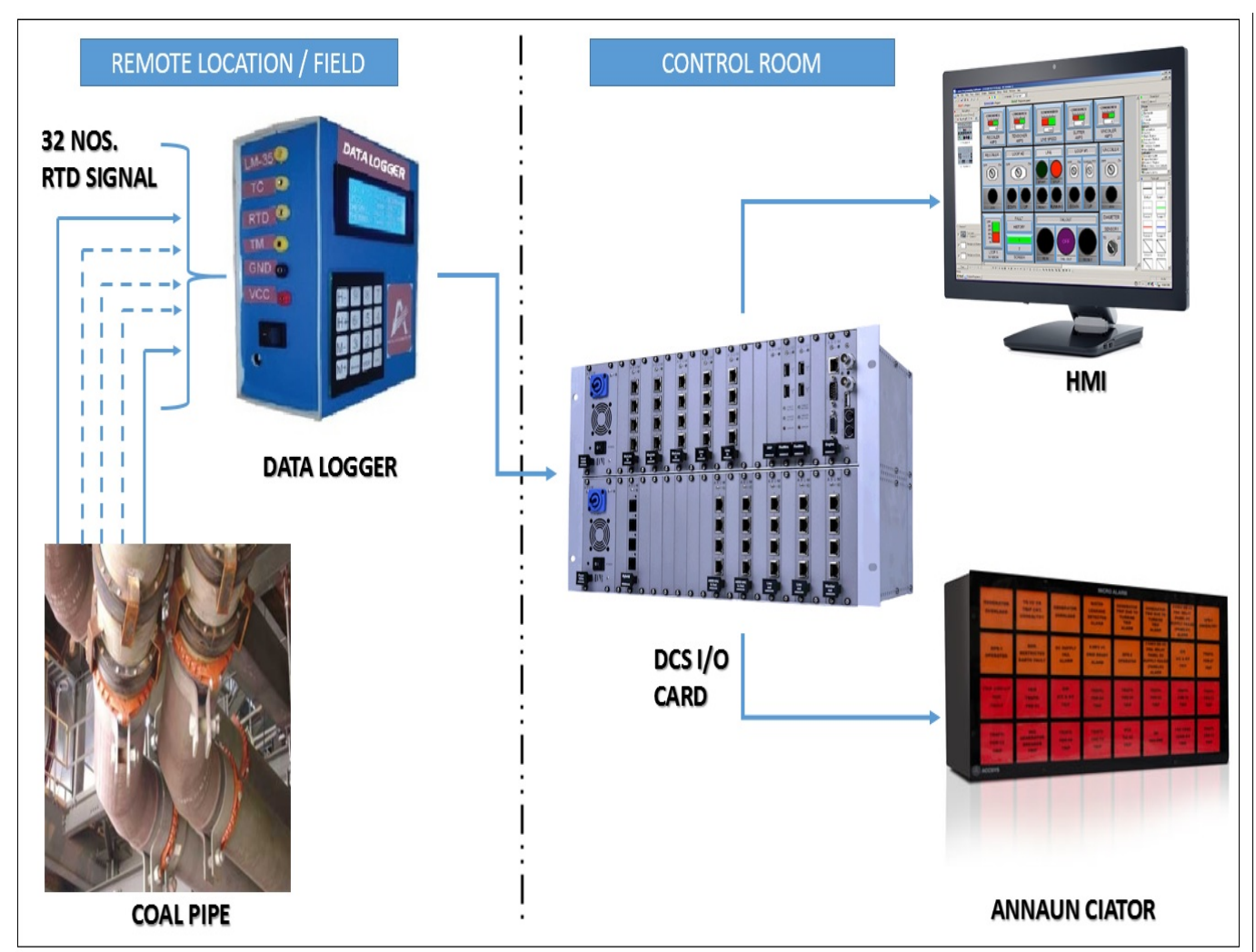

Fig. 3. Block diagram automation of coal pipe temperature measurement.

As per schematic diagram of Fig. 3, planning and arrangements has been made to execute the project towards final outcome. We arranged all the equipments like Data logger, Temperature scanner, RTD, Signal cable, Junction box, Man power, etc. Once all the material, equipments available on site, one by one we installed, commissioned them as per our scheme. And after some working days we could measure and monitor coal pipe temperature value from remote in continuous basis. We prepared a graphical representation of all temperature value in our existing DCS system for plant operator so that in any time they can see the temperature value of all 32 numbers of coal pipe of eight coal mill at a glance. We discussed with both Operator people and other engineering departments for the alarm limit of those temperature value so that if any probability of coal pipe choking, happens it will give us early alert. After discussion we configured alarm for annunciator panel such that if any running Coal Mill pipe temperature goes low, below $60 \circ \mathrm{C}$ it will flash an alarm called "Any coal mill pipe temperature low". Thus we were able to execute the project and established automation for remote monitoring and measurement of coal pipe temperature of coal mill of PF boiler.
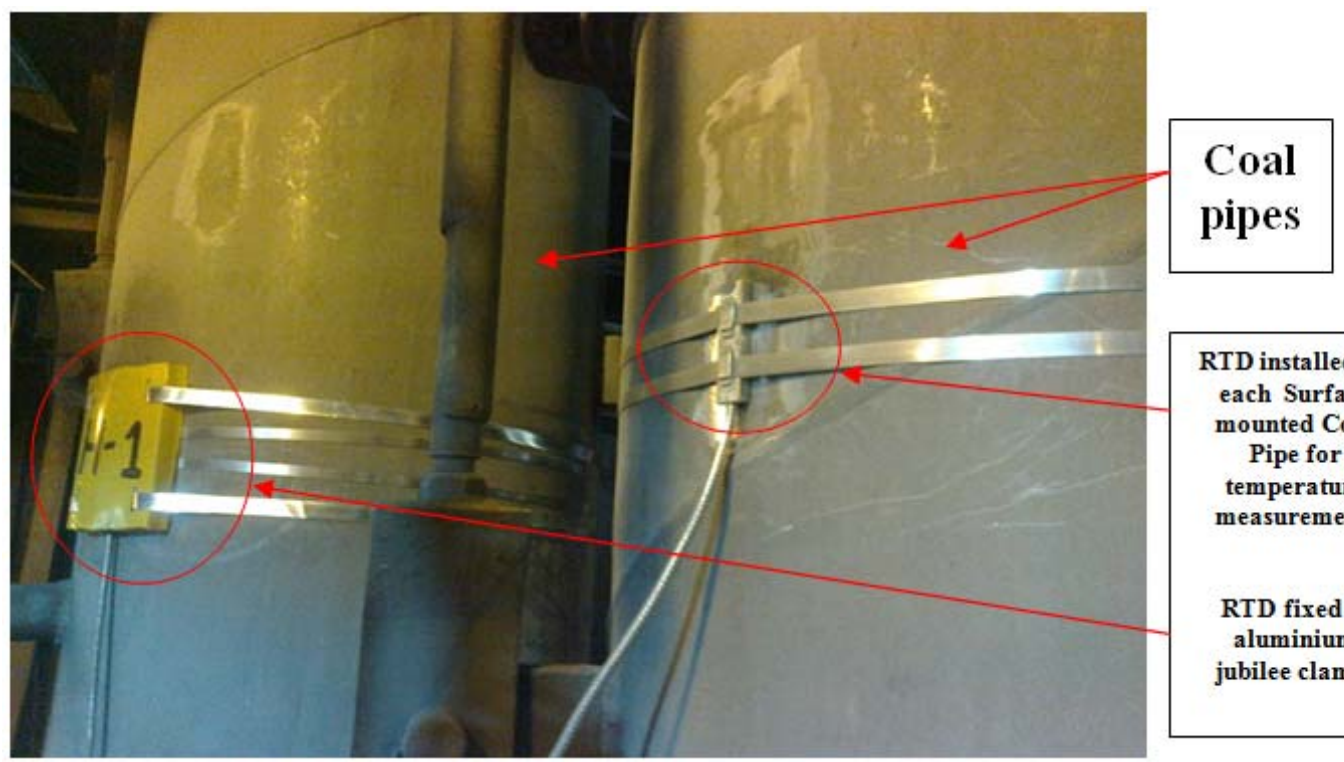

Fig. 4. RTD Mounted on Coal pipe For Temperature Measurement. 


\section{RESULTS AND DISCUSSION}

Operating a coal-fired boiler efficiently is all about carefully and constantly managing hot air flow which carries coal. it is seen that in our work that an operator can get alarmed if the temperature of hot air flow is low and it is easily rectified Fig.5 shows the how coal pipe temperature are displayed in the controlled room through distributed controlled system(DCS).

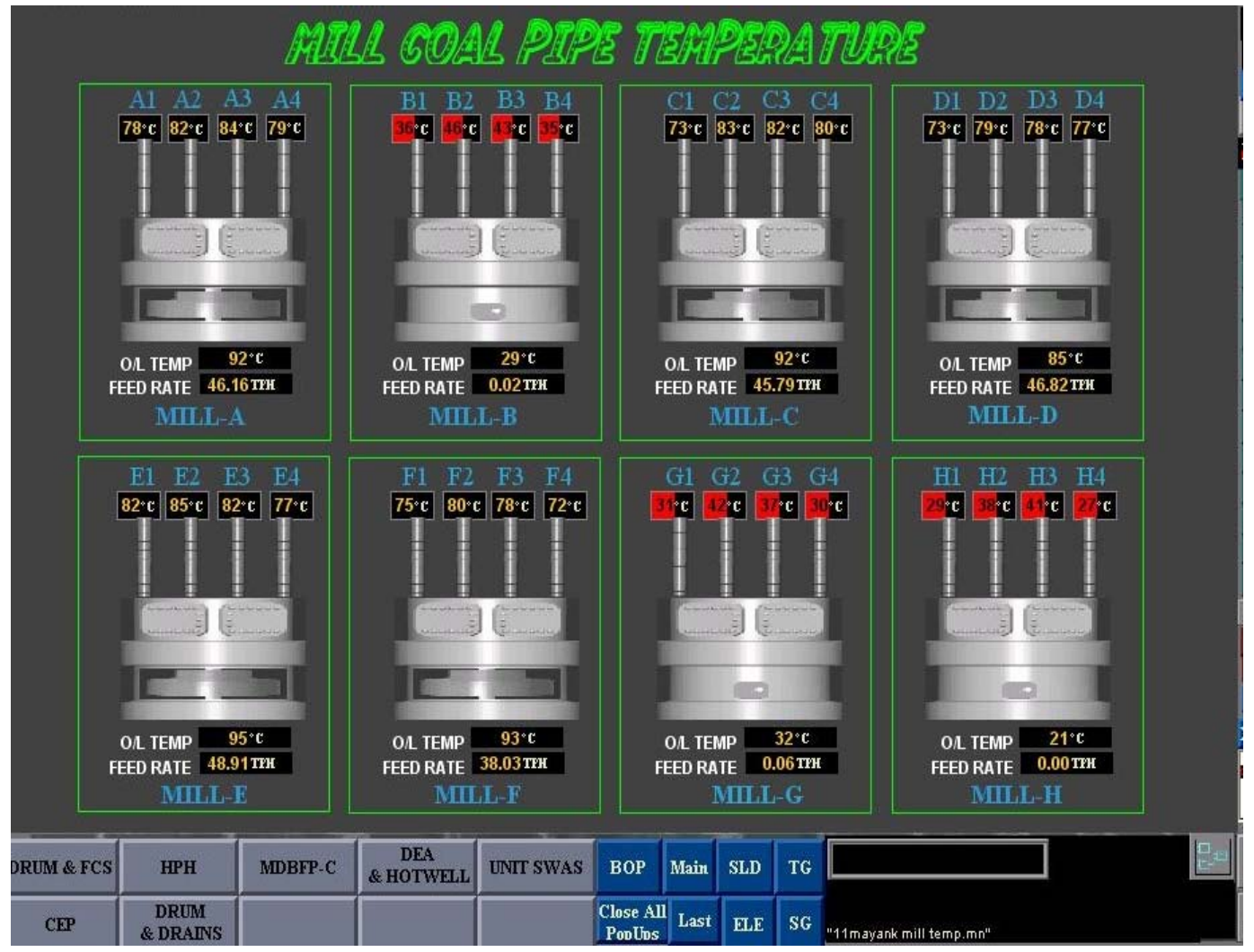

Fig. 5. Graphical Representation of Coal Pipe Temperature on DCS.

Now if the temperature of the coal flow pipe is beyond the limit of $65^{\circ} \mathrm{C}$ then an alarm will set and indicates to ensure for proper temperature maintaining to prevent pipe choking as shown in Fig. 6.

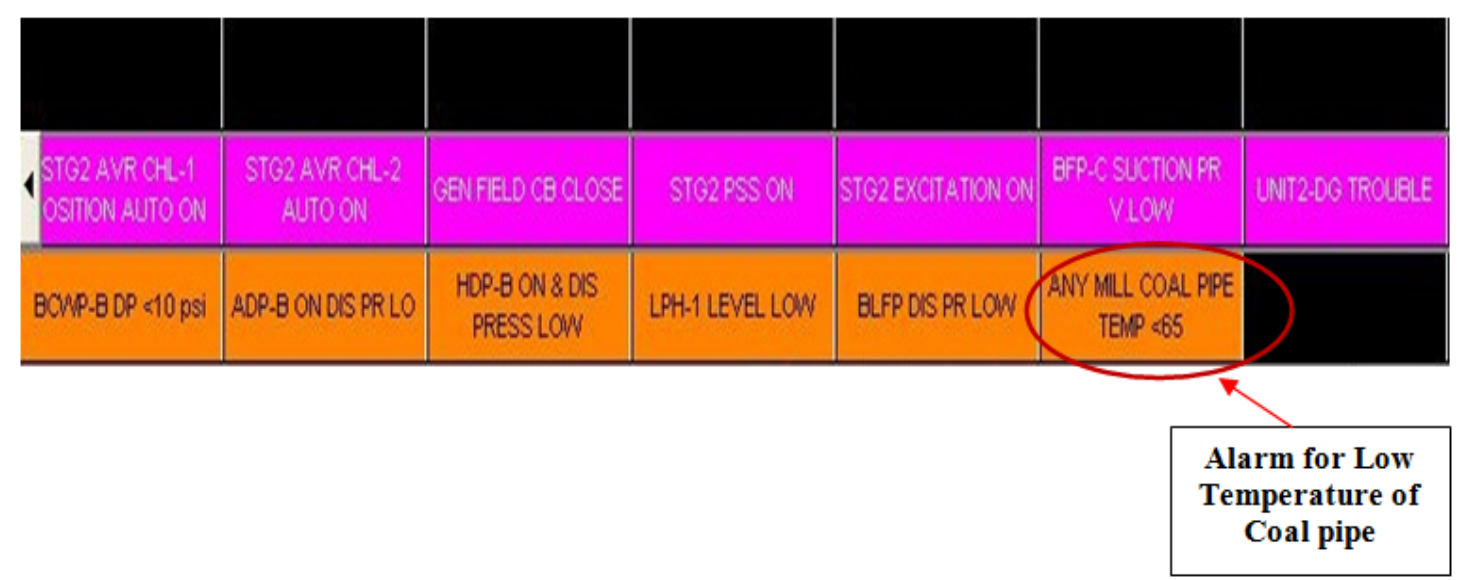

Fig. 6. Alarm Configured on Annunciation Panel.

\section{CONCLUSIONS}

Uninterrupted Power Supply is a basic demand for this new age. Again uninterrupted power can be provided by modernisation of power houses. Availability of equipments causes uninterrupted power generation from power plants. Each and every small parameters plays a vital role of equipment availability. As said, by successful completion of this project coal pipe temperature can be measured, monitored for a long time without any interruption and this directly increases the availability of coal mill as well as indirect source of uninterrupted power supply. So the Project leads us to the following advantages such as Continuous measurement/ monitoring 
of coal pipe temperature. Avoided Man dependency, and avoided human error. Frequency of coal pipe choking reduced.

Coal mill availability increased. New technology adopted for automation. Helped for early detection and analysis of coal mill related problems.

\section{REFERENCES}

[1] Damian Flynn, "Thermal Power Plant Simulation and control", The Institution of Electrical Engineers, 2003.

[2] K. E. Bollinger and H. R. Snowden, "The Experimental Determination of Coal Mill Models", IEEE Transactions on Power Apparatus and Systems, Vol. PAS-102, No. 6, pp. 1473-1477, 1983.

[3] J. L. Wei, J. H. Wang and Q. H. Wu, "Further study of coal mill modeling by machine learning based on on-site measurement", Proceedings of the 16th International Conference on Systems Engineering, pp. 741-746, 2003.

[4] T. Back, D. B. Fogel and Z. Michalewicz, "Handbook of Evolutionary Computation", Institution of Physics Publishing and Oxford University Press, 1997.

[5] Y. P. Chen, "Extending the Scalability of Linkage Learning Genetic Algorithms", Springer - Artificial Intelligence, Vol. $190,2004$.

[6] T. Back, "Selective pressure in evolutionary algorithms: A characterization of selection mechanisms", Proceedings of the First IEEE Conference on Evolutionary Computation, Vol. 1, pp. 57-62, 1994

[7] Y. G. Zhang, Q. H. Wu, J. Wang, G. Oluwande, D. Matts and X. X. Zhou, "Coal mill modeling by machine learning based on on-site measurement", IEEE Transactions on Energy Conversion, Vol. 17, No. 4, pp. 549-555, 2002.

[8] P. Zachariades, J. L. Wei and J. Wang, "Development of a Tube-ball Coal Mill Mathematical Model Using Particle Swarm Optimization", Proceedings of the World Congress on Engineering, Vol. I, 2008.

[9] Omar Mohamed, Jihong Wang, Shen Guo, Bushra Al-Duri and Jianlin Wei, "Modelling Study of Supercritical Power Plant And Parameter Identification Using Genetic Algorithms", Proceedings of the World Congress on Engineering, Vol. II, 2010.

[10] Heng Wang, Min-ping Jia, Peng Huang and Zuo-liang Chen, "A study on a new algorithm to optimize ball mill system based on modeling and GA”, Elsevier Energy Conversion and Management, Vol. 51, No. 4, pp. 846-850, 2010.

[11] M. et Alli, "Modeling of the Measurement of Flow Measurement of the Flow of Hot Air in Straight Tube of Blast Furnace," 39th Seminar of Reduction of Ore of Iron and Raw Materials, Ouro Preto, 22-26 November 2009, pp. 1-10. 